Session 3255

\title{
Collaborative Research and Curricula Development in the New M.S. Engineering Programs at Boise State University
}

\author{
Siddhartha P. Duttagupta, Paul Dawson, George Murgel, Joseph Guarino, \\ Christopher Pentico, Robert Walters, and Stephanie Eisenbarth
}

\author{
Boise State University
}

\begin{abstract}
The objective of this paper is to provide insight into the functioning of Boise State University's (BSU) three new M.S. programs in Engineering, namely, Civil (CE), Electrical (EE), and Mechanical (ME) Engineering. These programs were created as a result of a tremendous collaborative effort with partners from higher education, government, and industry. Notable examples include (i) \$12 million in a community funded effort to construct two new engineering buildings that became operational in 2000; (ii) $\$ 5$ million in laboratory equipment donations from Micron, HP, American Microsystems, SCP, Cascade Microtech, Teradyne, and Zilog; (iii) \$5 million in research and equipment grants in the Year 2000; (iv) development of four new "distance" graduate courses to be offered to the industry and the community-at-large via various video delivery modes; (v) participation of four industry experts as adjunct faculty for teaching BSU graduate courses; and (vi) 10,000 man-hours donated by industry engineers to train BSU faculty and technicians in the use of sophisticated laboratory equipment. The newly created M.S. programs in CE, EE, and ME are engaged in an interdisciplinary research effort, which is discussed in this article. The technical goal is to minimize the use of hazardous chemicals in cleaning high aspect ratio microstructures. Broader goals include dynamic curricula development, and student leadership and mentoring opportunities that will enhance the quality of graduate education and attract new students to the programs. This project symbolizes the commitment shared by the faculty and their partners in the industry and in the government to ensure the rapid, collaborative growth of professionally oriented graduate programs at BSU.
\end{abstract}

\section{Introduction}

In 1996, the State of Idaho transformed what had been a University of Idaho satellite-engineering program into a new College of Engineering at Boise State University. The B.S. degree programs in Civil, Electrical (renamed as Electrical and Computer Engg.- ECE), and Mechanical Engineering were established and were accredited by ABET in 1998. For the past four years, the College of Engineering has experienced rapid growth in facilities, faculty, and student

"Proceedings of the 2001 American Society for Engineering Education Annual Conference \& Exposition Copyright Ó 2001, American Society for Engineering Education” 
enrollment. Some program aspects, especially the initial development of the microelectronics laboratory facilities, have been documented. ${ }^{1}$ The State of Idaho recently approved the establishment of four new M.S. programs in Electrical, Computer, Civil, and Mechanical Engineering. The impetus to initiate each of these programs came principally from the demands of local citizenry, industry, and institutions to meet local technical education needs. This article will describe the efforts that have been undertaken by the Engineering faculty in partnership with the community as a whole, to ensure that these programs will adequately prepare students for engineering and other high technology careers with an emphasis on technology management.

\section{Development of M.S. programs}

The challenges faced when developing the new M.S. programs in Engineering at BSU were typical of any start-up graduate education program in a rapidly growing high-tech community. Indeed, Boise has recently been noted as the second fastest growing small cybercity in the United States. $^{2}$ An important need was to create the infrastructure that could handle the tremendous demand for higher education in the Boise area. A good indicator of potential growth of the graduate programs is the growth of the undergraduate engineering programs in the past four years. The combined student enrollment in ECE, CE, and ME grew from 60 in 1996 to 1,019 in 2000! The majority of the students are current or prospective employees of the hi-tech firms in Boise and in the Pacific Northwest region. This includes Micron Technology, Hewlett-Packard, Zilog, Micron Electronics, Jabil Circuits, Preco, American Microsystems, Amkor, SCP Global Technologies, Extended Systems, In-System Design, Teradyne, and Cascade Microtech. To attract and educate such a student population, especially those interested in pursuing a dissertation, it would be necessary to develop state-of-the-art facilities, and to hire faculty with expertise in "hot areas". Since the majority of the students are non-traditional, it would be necessary to reach them using a distance learning setup. In addition, there was a need to quickly develop a robust research program, which would help attract traditional graduate students and large-scale external funding, and ensure that the curricula and facilities are continuously updated. The goal was to develop professionally-oriented, practical-experience based programs, which can readily incorporate cutting edge research and development into the curricula, and are conveniently accessible to the community. The key elements of the on-going program building effort which are described below include development of infrastructure, laboratories, distance learning courses, and a graduate research program, and innovative ways to recruit and retain faculty.

\section{i) Partnerships for infrastructure development:}

In preparing for graduate programs while the undergraduate programs were only three years old and growing rapidly, the College of Engineering anticipated a severe shortage of space for offices, labs, and classrooms. In addition, there were specialized needs for graduate education in hi-tech fields such as superior computing resources and distance learning equipment. With help from the community, BSU was able to formulate a plan that addressed these issues. Two new buildings for the College were added in 2000 at a cost of 14 million dollars. The 64,000-squarefoot Micron Engineering Center (MEC) houses classrooms, faculty offices and state-of-the-art

"Proceedings of the 2001 American Society for Engineering Education Annual Conference \& Exposition Copyright Ó 2001, American Society for Engineering Education" 
laboratories for electronics, mechanical instrumentation, digital circuits, thermal and fluid dynamics, traffic and transportation and other areas of study in electrical, computer, civil, and mechanical engineering. The Harry W. Morrison Civil Engineering Building features more than 10 specialized laboratories for civil and mechanical engineering and construction management. The 14,000-square-foot structure includes a 6,000-square-foot high bay available to house student/faculty design and construction projects. While private individuals made significant contributions, the primary external contributors were Micron Technology (\$6 million) and the Harry Morrison Fund (\$2 million). Funding was also made available to upgrade the facilities of the existing Engineering Technology (ET) building for high speed (384 Kbps) compressed video connection for sending and receiving distance learning courses.

\section{ii) Laboratory development:}

One of the distinguishing features of the graduate (and undergraduate) engineering programs at BSU is the extraordinary emphasis that has been placed in laboratory development. This was driven by the conviction that while labs tend to be time intensive, and very expensive to develop and to maintain, the payoff comes in the hands-on experience the students gain and the cooperative learning those labs inspire. The strategy has helped BSU to be extremely responsive to the needs of the hi-tech industries. In return, these organizations have invested an extraordinary amount of resources in program development. This includes participation in the College of Engineering Advisory board, joint appointment programs, equipment grant awards, donations of new and used equipment and technician time, development of on-site distance education classrooms to receive BSU courses, and providing access to their own laboratories and personnel for research and for education purposes. The development of the two main lab entities is described below.

\section{CAD/Computational laboratories:}

Engineering faculty led by Dr. Erickson and Dr. Guarino have successfully applied for a equipment grants from Hewlett-Packard totaling \$2.5 million, which provided computing resources to support advanced design (CAD) and modeling applications in electrical and mechanical engineering. The present facilities include a network of four UNIX servers with one gigabyte of memory and 34 gigabytes of data storage, and 22 UNIX workstations and 100 PC workstations. CAD tools are available college-wide at sites in ET and MEC buildings, and in several faculty and staff offices. The current practice is to provide a central resource for file, compute and license serving for instructional needs, as well as distributed computing and graphical resources for research needs. The facilities are utilized by ten graduate courses in ECE and ME.

\section{Microfabrication laboratory:}

The large concentration of microelectronics companies in Boise and in the region provided the impetus for BSU to develop a microfabrication laboratory comparable to ones that exist in wellendowed prestigious programs such as UC Berkeley, M.I.T., and Georgia Tech. Given the

\footnotetext{
"Proceedings of the 2001 American Society for Engineering Education Annual Conference \& Exposition Copyright
} Ó 2001, American Society for Engineering Education" 
limited resources available, this was a very ambitious goal, if not for the assistance of BSU's industrial partners. BSU provided \$250,000 to initiate the Idaho Microfab Lab with the understanding that the faculty will have to apply to outside agencies to acquire equipment costing in the range of $\$ 100,000$ to several million dollars! This is an ongoing effort involving the participation of several faculty members- Dr. Duttagupta, Dr. Burkett, Dr. Parke, and Dr. Erickson. The laboratory is divided into three sub-facilities: Fabrication, Characterization, and Test, and hosts five graduate courses and eight undergraduate courses. The resources are also utilized by the 2-year Sematech-supported Semiconductor Technology program in the College of Applied Technology at BSU.

The fabrication facility is a Class 1000 cleanroom for teaching and research in semiconductor wafer processing and microstructure fabrication. The lab supports wafer cleaning, etching, lithography, and sputtering. Metrology capability is supported in the area of ellipsometry, resistivity measurement, and optical and scanning electron microscopy. The current equipment includes an SCP wet process bench, an SVG photoresist coat and develop track, a barrel etcher, a GCA 8000 wafer stepper, and a CRC sputtering system. The equipment was donated by companies such as Micron Technology, Motorola (Austin division), Zilog, Micron Electronics, American Microsystems, and SCP Global Technologies. The estimated value of the donated new and used $150 \mathrm{~mm}$ wafer processing equipment is $\mathbf{\$ 3}$ million.

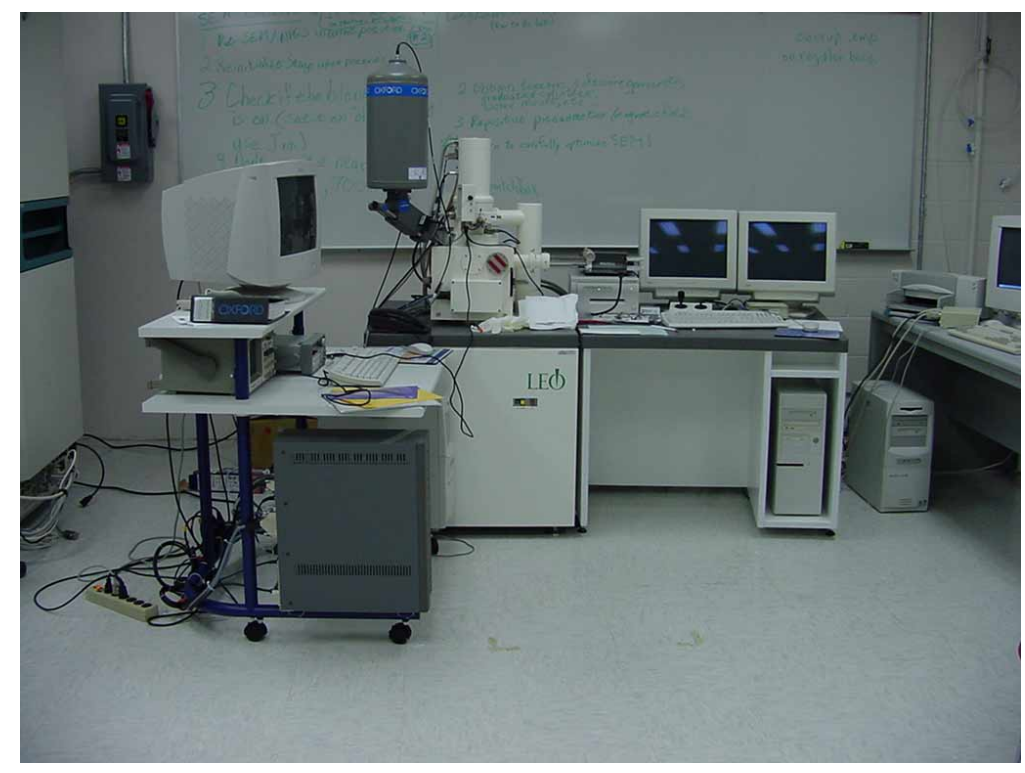

Figure 1. LEO 1430 VP Scanning Electron Microscope System with nanoscale imaging, analysis, and patterning capability

The following additional tools have been acquired through $\mathbf{\$ 3}$ million in grant monies in 19992000 and will be operational in 2000-2001. Dr. Duttagupta and fellow faculty have been awarded two NSF-Idaho EPSCoR instrumentation grants to acquire a multi-purpose Scanning Electron Microscope (Figure 1.) with nanoscale imaging, analysis, and patterning capability, and a Double Sided Mask Aligner which is a key tool for the fabrication of MEMS devices. Dr. "Proceedings of the 2001 American Society for Engineering Education Annual Conference \& Exposition Copyright Ó 2001, American Society for Engineering Education" 
Parke and Dr. Erickson have acquired a Rapid Thermal Processor system funded by an NSF EPSCoR grant. Dr. Burkett has acquired a High Aspect Ratio Etch System funded by a DARPA grant. In January 2001, Micron Technology announced the donation of a $\mathbf{\$ 5 0 0 , 0 0 0}$ Chemical Mechanical Planarization tool to BSU. Partnerships have been formed with the Rochester Institute of Technology, Rochester, NY to perform the processing steps not yet available at BSU.

The device characterization lab was made possible by donations from Micron, AMI, Cascade Microtech, and HP, along with venture capital funding of \$2.5 million awarded to Dr. Parke and Dr. Erickson in 2000. It contains three complete IV/CV wafer probing stations, where 150$200 \mathrm{~mm}$ silicon wafers are micro-probed, electrically characterized, and modeled. Each station is equipped with an Alessi manual prober, HP4155 parameter analyzer, and HP4284 LCR meter that are GPIB networked to PC's. BSIMPro software is used to drive the equipment, take data, and extract BSIM3 SPICE model parameters for deep-sub-micron MOSFET's and BJT's. Probes are triax-connected and EMI shielded for low-noise measurements. Measured electrical characteristics are used to study device physics and to develop accurate mathematical models for the device behavior. Recently, a new Cascade Summit Microwave wafer probe station and an HP85122A RF Device Modeling system were added to this lab, for performing on-wafer, Sparameter analysis of high-performance devices up to $20 \mathrm{GHz}$. This equipment is interfaced to an HPUX workstation running IC-CAP device modeling software.

The device test facility was created in the Fall of 2000, and is equipped with a brand new $\mathbf{\$ 7 5 0 , 0 0 0}$ J995 Memory and ASIC Automated Test System donated to BSU by Teradyne and Micron Technology. This system allows students to write test programs with appropriate test vectors and/or patterns and will be used to test both off-the-shelf IC's as well as studentdesigned, MOSIS-fabricated IC projects.

Equipment operational support: The industrial partners have also provided considerable assistance to ensure the optimum use of the tools acquired by the Microfab. Technicians and engineers from Micron, Zilog, and SCP have provided BSU faculty and technicians with more than 10,000 person-hours of training time. These companies have also arranged for donations from their own suppliers! This includes expensive consumables such as photoresist from Shipley as well as Teflon carriers from Entegris.

\section{iii) Distance learning:}

One of the most important aspects of the BSU-industry partnerships has been the development of distance learning courses by the faculty as a means of attracting graduate (and undergraduate) students who are employees of regional companies. At present there are four graduate courses (and seven undergraduate courses) that are taught in this fashion. The courses currently offered are- Advanced CMOS Device Design (EE 520), Integrated Circuit Physical Design (EE 510), VLSI Design (EE 512), Advanced Integrated Circuit Processing (EE540). The list of instructors includes Dr. Duttagupta, Dr. Parke, Dr. Burkett, and Dr. Baker in the ECE department. The

"Proceedings of the 2001 American Society for Engineering Education Annual Conference \& Exposition Copyright Ó 2001, American Society for Engineering Education” 
medium of instruction currently is two-way audio and one-way video. The equipment used for broadcasting is operated by the BSU Instructional Technology Fixed System (ITFS) and uses a Very High Frequency (5 MHz) Microwave/Cable system, and a fiber optic broadband digital cable system. The broadcast is available to WBS/Sprint and AT\&T Broadband cable subscribers in Boise. Local companies such as Micron Technology and Zilog have equipped specialized classrooms with the necessary microwave equipment, to enable their employees to receive these courses on-site. A BSU courier service delivers any hard copy materials, though assignments and exams are increasingly being administered online. For companies such as American Microsystems in Pocatello, Idaho, courses may only be received by videotape.

Initially, the distance learning concept met with stiff resistance amongst students and faculty alike. There were also several technical glitches. The main problem has been to create an environment that is friendly to both the in-class and remote students. This is an on-going learning process for the faculty, but it is especially difficult for students who are introduced to this type of instruction for the first time. The companies have helped by providing on-site assistants, who are trained on the use of the communication equipment.

In the Fall of 2001, plans are to use the compressed video delivery facility in the College of Engineering to broadcast some distance learning courses. Finally, the success of undergraduate online courses has led to plans to offer at least one online graduate course by the Spring of 2002.

\section{iv) Graduate research:}

A graduate research program, however modest, can have a considerable impact on the level of graduate education that is imparted to the students. This is especially true for interdisciplinary research, where students are required to learn the basics of technology management. Externally funded programs attract more "traditional" graduate students, even though some current "nontraditional" students have profited by working on "open" projects that are mutually beneficial to BSU faculty and the students' company supervisors. Traditional students are of immense help in developing new software or creating operating procedures for lab equipment and as an aid to the technical staff in helping maintain the equipment. These activities ensure an enriching laboratory experience for even non-thesis students. In the absence of $\mathrm{Ph}$. D. students, the College of Engineering has currently recruited as many as 10 post-doctoral fellows (PDF), who possess expertise in selective areas of technology. In one instance, a PDF was recruited as an adjunct faculty to teach a course (EE513- RF IC Design), since he was the most qualified person to do so! The same applies to engineers at Micron, Zilog, and SCP, who were originally research collaborators and have all taught as adjunct faculty. Finally, funded programs will help raise the profile of BSU nationally and internationally, and can create a more diverse student body (including international students) at BSU.

For all of the above reasons, the Engineering faculty members have been strongly encouraged to pursue research activities, especially focussing on the training of the graduate students in cutting edge applications. External funding from federal, state, companies and venture capital funding

"Proceedings of the 2001 American Society for Engineering Education Annual Conference \& Exposition Copyright Ó 2001, American Society for Engineering Education” 
totaled \$5.3 million in 2000 alone. This is a considerable achievement, for a nascent graduate program. More details on the specific impact of an interdisciplinary research project on graduate studies at BSU are provided in Section III.

\section{v) Faculty recruiting and retention strategies:}

BSU and other Idaho universities have determined that they need to be highly creative while planning to recruit faculty and retain them for an extended tenure. The reason for this is primarily the low salaries for faculty, which becomes increasingly non-competitive at senior levels. Idaho faculty salary averages are the fifth lowest in the nation, ${ }^{3}$ and are $14 \%$ lower than peer institutions in the region. ${ }^{4}$ Thus BSU faculty are migrating to positions in the high-tech industries which pay as much as $35 \%$ more than current salaries. ${ }^{4}$ The associated higher turnover of faculty affects graduate as well as undergraduate students because repeated job searches divert considerable time and resources of existing faculty away from teaching and research responsibilities. Some programs such as Computer Engineering have been unable to find qualified applicants in the initial search and are forced to engage in costly re-advertisement for some positions multiple times. Resources are often spent on training new faculty members who have left when compensation does not keep up with national trends.

Faced with a severe problem of recruiting qualified faculty in "hot areas", the College of Engineering has shown a remarkable flexibility in attracting people, and in its four year tenure has not had a single faculty member leaving voluntarily. Admittedly, this is too short a time period to measure success and determine its causes, but some trends are definitely emerging.

Recruiting dual-career couples: In the 1999 ASEE symposium, Dr. Burkett (ECE, BSU) and colleagues discussed issues facing dual career couples in the field of science and engineering. ${ }^{5}$ From the case studies presented, the conclusion was that finding two tenure-track positions in the same University is a difficult task. There are thus significant advantages in recruiting qualified couples. It is likely that a substantial loyalty will result when a university makes this type of commitment, and it is also likely that both will be extremely productive faculty members in such a supportive environment.

Dr. Burkett's case studies included herself and two other couples at Pennsylvania State University and the University of Alabama. In 2001 the College of Engineering at BSU alone will have three dual career couples! This includes Dr. Burkett (ECE) and Dr. Lusth (Computer Science, program will relocate in the College this Fall); Dr. Moll (ME) and Dr. Knowlton (ECE); and Dr. Barney Smith (ECE) and Dr. Smith (ECE). The ECE department was especially supportive in the case of Dr. Smith who has a Master's degree in Electrical Engineering and a Ph.D. degree in Economics from Rensselaer Polytechnic Institute, Troy, New York. He was initially recruited as an adjunct faculty to teach Computer Engineering courses, but was soon promoted to the position of Visiting Assistant Professor. In addition to fulfilling his teaching and research responsibilities, Dr. Smith is simultaneously pursuing a doctoral degree in Computer Engineering at the University of Idaho. The wisdom of this selection is apparent when

"Proceedings of the 2001 American Society for Engineering Education Annual Conference \& Exposition Copyright Ó 2001, American Society for Engineering Education" 
considering that the College has an unfilled position for a Computer Engineering faculty for more than a year to date.

All of the aforementioned faculty members have established strong teaching and research track records at BSU with grant awards totaling \$2.5 million in 2000 as well as a Best Teacher award nomination (Dr. Burkett).

Partnerships with local companies: Another strategy that has worked very successfully so far is to form partnerships with the same hi-tech companies that threaten to recruit BSU faculty! Dr. Baker (ECE) was recently recruited on the condition that he can work one day a week and during summer at Micron Technology. The University created a special position for Dr. Buffenbarger in Computer Science whereby he can spend $50 \%$ of his time working for BSU and the remaining $50 \%$ working for Hewlett-Packard. Dr. Parke (ECE) has recently accepted the position of the Chief Technical Officer of Wireless Incorporated, a new start-up company, while continuing his career at BSU. Dr. Rafla (ECE) is an employee of Micron and has previously worked for Hewlett-Packard. In addition to monetary compensation, these faculty members are taking full advantage of the professional development opportunities presented to them. This is ultimately beneficial to Engineering graduates, who have the opportunity to work in "hot areas" and are also eagerly recruited by companies nationwide.

In the reverse situation, companies have also been very flexible in allowing their employees to work as adjunct faculty at BSU. Several graduate (and undergraduate) courses have been taught by specialists from Micron (Richard Holscher), HP (Kenneth Boorom, James Buffenbarger), SCP (John Rosato), and Zilog (Timothy Carns). Numerous others have availed of guest lecturing opportunities. Student evaluations have consistently indicated that the practical experiences provided by these instructors were highly valued.

\section{The HART project}

The following is a small research project that has been chosen as an example of the novel ways of interaction that are being encouraged as part of the graduate studies in the College of Engineering. The anticipated impact on graduate curricula and student skill sets is also discussed.

The project was initiated in the Fall of 2000 as a 2-dimensional modeling venture of vapor drying processes in high aspect ratio trenches (HART) in a semiconductor manufacturing facility. The participating ME researchers were Dr. Dawson (ME faculty), and Robert Walters, a graduate student and technician with the College. In the past few months, it has rapidly grown in scope, with the involvement of additional M.S. programs and an expanded list of activities that includes microelectronic process experiments for model validation (ECE), and hazardous waste analysis (CE). The ECE participants are Dr. Duttagupta and Christopher Pentico (graduate student), while the CE participants are Dr. Murgel and Stephanie Eisenbarth, a graduate student and an employee of the Bureau of Reclamation office in Boise, Idaho. Current funding for the proposal is through an Infrastructure Grant from the State of Idaho (Principal

"Proceedings of the 2001 American Society for Engineering Education Annual Conference \& Exposition Copyright Ó 2001, American Society for Engineering Education" 
Investigator: Dr. Guarino, ME, BSU), with matching grants from the ECE, ME, and CE programs. Additional resources for the project are being provided by active projects funded through the National Science Foundation and the Inland Northwest Research Alliance (INRA). Technical assistance for the project is being provided by SCP Global Technologies, a Boise based manufacturer of wet processing equipment for the semiconductor industry.

\section{i) Summary description of proposal:}

The fluidic processes associated with wafer processing are an integral part of semiconductor device processing technology. Aqueous based processing accounts for over half of the process steps associated with semiconductor device manufacturing. Little is known regarding the detailed behavior of fluids while vapor drying high aspect ratio trenches (HART). The aqueous process of wetting charged silicon surfaces with a chemical, displacing the chemical with a rinsing fluid, and then displacing the rinsing fluid with a drying agent is not completely understood at the submicron level. As device performance increases, trench depth must also grow to allow access to more device layers. The drive to shrink device size forces trench width to decrease. These combined constraints result in sharply increased aspect ratio trenches. As trench aspect ratio grows, critical processing steps like etching, cleaning, rinsing, and drying become more challenging due to the confining nature of the very deep and very narrow trenches.

The development of computational models for each step of the aqueous process will greatly enhance the current understanding of the dominant physical mechanisms and chemical processes at work. This knowledge can then be applied to the optimization of these processes. It can also be used to identify future technology paths for aqueous processing.

In order to validate trends predicted by the above model, experiments observing actual drying events on $150 \mathrm{~mm}$ wafers will be performed in the Idaho Microfab lab facility. The creation of high aspect ratio structures will require careful processing. Sub-micron etch structures may be created in photoresist with the nanopattern generator attachment of the LEO 1430 VP Scanning Electron Microscope in the Microfab. The evaluation of the drying process can be performed by the same instrument utilizing its nanoscale imaging and analysis capabilities. The experiments will be structured using experimental design, in order to provide a detailed impact analysis of the various parameters (drying time, aspect ratio of trenches, rinsing agents, drying agents) that influence the drying process.

Finally, the environmental impact of the drying process will be evaluated. The investigation will document the efficiencies of rinsing and drying agents and also determine the environmental impact of the above agents, which are frequently hazardous chemicals. The goal is to provide processing recommendations that will ensure efficient cleaning of HART structures and will be environmentally benign.

"Proceedings of the 2001 American Society for Engineering Education Annual Conference \& Exposition Copyright Ó 2001, American Society for Engineering Education" 


\section{ii) Impact on graduate curricula:}

As part of the funding requirements, the graduate students (Pentico, Walters, and Eisenbarth) will also perform as teaching assistants/student leaders in associated courses offered by ECE (EE 540/L- Advanced IC Processing), ME (ME 530- Fluid Mechanics), and CE (CE 520/LAdvanced Environmental Engineering Processes \& Design). The curricula for these courses have been planned so that they incorporate findings from the ongoing project activity. The graduate students enrolled in these courses will also participate in the project and learn from it. The anticipated benefits as follows:

This project enforces the concept of a "dynamic curricula content" in graduate courses. In other words, the student will experience the continuous "learning on the job" aspect of today's high-technology fields, where assumptions and predictions printed in textbooks are often set aside in face of new data.

The three graduate students will be extensively exposed to issues related to technology management. They will have to interact with each other in a highly interdisciplinary project, adjust to each other's widely different background and specialization, and will have to demonstrate leadership in guiding fellow graduate students in individual projects. This will prepare them ideally for future careers that they may decide to pursue in industry, academia, or in the government.

\section{Conclusions}

The new M.S. programs in Engineering at BSU are growing dramatically and exploring new ways to do business in the high-tech economy of today. Graduate education has become a very complex affair, where students have to be exposed to rapidly changing technologies, and have to master project management skills as well. This cannot be simply accomplished by allowing engineering majors to minor in business or vice versa. It is anticipated that a lab intensive curricula, and student management of interdisciplinary projects, may help prepare students adequately for a wide variety of career opportunities. Such a strategy requires the Universities to be creative in recruiting talented faculty, who in turn should explore all possible avenues to develop excellent research and educational programs, with frequent input from their compatriots in the industry.

\section{Bibliography}

1. Parke S., Duttagupta S.P., Burkett S., and Hofhine M., Microelectronics Education and Research in the Idaho Microfabrication Lab at Boise State University, Proceedings of the Biennial University/Government/Industry Microelectronics Symposium, v. 13, p 17, June, 1999.

\footnotetext{
"Proceedings of the 2001 American Society for Engineering Education Annual Conference \& Exposition Copyright
} Ó 2001, American Society for Engineering Education” 
2. Report by the American Electronics Association and the NASDAQ Stock Market, December 5, 2000.

Subsequently quoted by the Idaho Statesman, p.1A, December 6, 2001

3. Report published by the American Association of University Professors March/April, 1999. Archived at this URL: http://www.isu.edu/departments/fsen/notices/ichefletter.htm

4. Report published by the Idaho Council of Higher Education Faculty (ICHEF), November 23, 1999. Archived at this URL: http://www.isu.edu/departments/fsen/notices/ichefletter.htm

5. Burkett S.L., Lusth J.L., Ruhala L.A., Ruhala R.J., Vrbsky S., and Hyslop B., ASEE Symposium Proceedings, Session 3675, 1999.

\section{Biography}

SIDDHARTHA P. DUTTAGUPTA, Ph.D.

Dr. Duttagupta is an Assistant Professor of Electrical and Computer Engineering at Boise State University. His area of expertise is in semiconductor device technology. His current research involves the fabrication of MEMS sensors for the detection of subsurface contaminants.

PAUL DAWSON, Ph.D.

Dr. Dawson is a Professor in the Mechanical Engineering Department at Boise State University. His specialties are fluid mechanics, atmospheric dynamics, turbulence modeling, and computational fluid dynamics. His current research involves modeling winter precipitation and cold season flooding events. He has previous experience developing turbulence models and air pollution models.

GEORGE MURGEL, Ph.D. P.E.

Dr. Murgel is an Associate Professor in the Civil Engineering Department at Boise State University with a private sector background and research interests in Environmental Engineering. Dr. Murgel currently has a project for the U.S. Bureau of Reclamation to collect water quality samples on three tributaries to the Snake River and assess the results in relation to the proposed Snake River and Brownlee Reservoir TMDL limits.

JOSEPH GUARINO, Ph.D. P.E.

Dr. Guarino is a Professor and Chair in the Mechanical Engineering Department at Boise State University. His research interests include engineering education, vibrations, acoustics, biomedical imaging and data processing.

\section{CHRISTOPHER PENTICO}

Mr. Pentico is a graduate student in the department of Electrical and Computer Engineering.

\section{ROBERT WALTERS}

Mr. Walters is a graduate student in the department of Mechanical Engineering and is also a Support Technician with the College of Engineering at Boise State University.

\section{STEPHANIE EISENBARTH}

Ms. Eisenbarth is a graduate student in the department of Civil Engineering and is also an Environmental Engineer Trainee with the U.S. Bureau of Reclamation.

"Proceedings of the 2001 American Society for Engineering Education Annual Conference \& Exposition Copyright Ó 2001, American Society for Engineering Education" 